\title{
SOBRE NOBLEZA, RENTAS REGIAS Y SEÑORÍOS EN CASTILLA LA VIEJA C. 1290-C. 1350
}

\author{
ON THE NOBILITY, ROYAL TAXES AND LORDSHIPS \\ IN CASTILLA LA VIEJA C. 1290-C. 1350
}

\author{
IGNACIO ÁLVAREZ BORGE \\ Universidad de La Rioja \\ http://orcid.org/0000-0002-7468-1334
}

\begin{abstract}
Resumen: Nuestro objetivo en este trabajo es estudiar la relación entre las rentas que recibían los nobles, asignadas sobre las rentas regias en ciertos lugares (situados) y el poder señorial. Para ello compararemos la información de las cuentas de Sancho IV que se conservan para finales del siglo XIII (1292) y la del Becerro de las Behetrías para mediados del siglo XIV (1352) en relación con algunos territorios que conocemos bien por nuestros trabajos anteriores. Ambos textos nos permiten abordar el estudio de esos aspectos en un período muy importante en el desarrollo de la relación entre el poder regio y el poder nobiliario. Un período de cambios y transformaciones marcado por la crisis y los conflictos desde las últimas décadas del siglo XIII.
\end{abstract}

Palabras clave: señoríos, nobleza, Castilla, situados, tributos.

Abstract: This paper aims to study the relationship between the money rents received by the nobility, assigned on royal taxes in certain places (situados) and seigneurial power. In order to do so, the information in the account books of Sancho IV that are preserved for the late $13^{\text {th }}$ century (1292) and that of the Becerro de las Behetrías for the mid- $14^{\text {th }}$ century (1352) will be compared, focusing on areas that we know well from previous works. Both texts enable us to address the study of these aspects in a very important period in the development of the relationship between royal and noble power, a period of changes and transformations marked by crisis and conflict from the closing decades of the $13^{\text {th }}$ century onwards.

Keywords: lordships, nobility, Castile, money-fiefs, royal taxes.

\section{SUMARIO}

1. Introducción.- 2. Beneficiarios de situados en 1292.- 2.1. Eclesiásticos, criados y oficiales regios.- 2.2. Caballeros.- 2.3. Ricoshombres y familia real.- 2.4. Otros aspectos del pago de situados: pirámide vasallática y cambios en los pagos.- 3. Situados en villas en 1292 y señoríos en 1352.- 3.1. Abadengos.- 3.2. Solariegos.- 3.3. Behetrías.- 3.4. Realengos.- 4. Conclusiones.- 5. Bibliografía citada.- 6. Apéndice de tablas. 


\section{INTRODUCCIÓN}

Nuestro objetivo en este trabajo es estudiar la relación entre los situados (las rentas que recibían los nobles, asignadas sobre las rentas regias en ciertos lugares) y el poder señorial de los nobles que los recibían. Para ello, fundamentalmente, compararemos la información de las cuentas de Sancho IV que se conservan para finales del siglo XIII (1292) y la del Becerro de las Behetrías para mediados del siglo XIV (1352) en relación con algunos territorios que conocemos bien por nuestros trabajos anteriores. Ambos textos nos permiten abordar el estudio de esos aspectos en un período muy importante en el desarrollo de la relación entre el poder regio y el poder nobiliario. Un período de cambios y transformaciones marcado por la crisis y los conflictos desde las últimas décadas del siglo XIII ${ }^{1}$.

Es bien conocido cómo una parte muy importante de los ingresos de los nobles, sobre todo de los altos nobles, en la Baja Edad Media procedía de las rentas y pensiones que recibían de los tributos de la hacienda regia ${ }^{2}$. La publicación de unos libros de cuentas de Sancho IV de 1290-1292 ha mostrado la enorme importancia de los situados ya en su reinado. Una importancia que igualmente se refleja en las crónicas de Alfonso X, Sancho IV, Fernando IV o Alfonso XI, que también se refieren con abundancia a estas cuestiones; o, como destacó Carlos Estepa, asimismo en algunas reuniones de Cortes, como en las de Carrión de 1316-1317 en la minoría de Alfonso XI ${ }^{3}$. En otro trabajo hemos intentado mostrar cómo ya en el reinado de Alfonso VIII (1158-1214) vemos que el sistema de asignación de situados y de pago de soldadas comenzaba a desarrollarse; un sistema en cuyos orígenes, como es conocido, hay destacar la importancia de los cobros de parias en la segunda mitad del siglo $\mathrm{XI}^{4}$.

En cualquier caso, los libros de rentas de Sancho IV que publicó F.J. Hernández, junto a otros libros de cuentas también del mismo rey, dan cuenta del enorme peso que el pago de soldadas y situados tenía en el sistema hacendístico castellano a finales del siglo XIII ${ }^{5}$.

\footnotetext{
${ }^{1}$ González 2012; Estepa 2007 y Monsalvo 2019, pp. 242-249.

${ }^{2}$ No podemos desarrollar ahora ese asunto con el detenimiento que merece, ni dar cuenta de la bibliografía de referencia con un mínimo de detalle. Baste decir, en todo caso, que, aunque es una idea bien conocida y válida con carácter general, es necesario establecer matices en función de los niveles y tipos de nobleza y de las distintas zonas geográficas. Para algunas referencias véase Álvarez 2016, pp. 114-120. Para un estudio detallado (y con abundantes referencias bibliográficas) sobre la relación entre la nobleza y la monarquía en la Baja Edad Media, véase Monsalvo 2017.

${ }^{3}$ Estepa 2007, p. 85. Las crónicas en Rosell 1953.

${ }^{4}$ Álvarez 2015; Estepa 2015. Con carácter general, Grassotti 1969, vol. 2, pp. 721-926. Sobre las parias, Pastor 2002; y véase ahora también Negro 2018.

${ }^{5}$ Hernández 1993, donde el autor publica un libro de rentas de Castilla (1292), de tributos de los judíos de Castilla (1290-1291), de rentas de León (1290), de tributos de los judíos de León
} 
¿Cuál era la relación entre los situados y los derechos señoriales? ¿Eran realidades que se desenvolvían de forma paralela y sin interferencias o conexiones entre ellas? ¿O, por el contrario, contribuían los situados a reforzar el poder señorial de los nobles beneficiarios? Esas preguntas conducen las consideraciones que dan contenido a estas páginas. Para avanzar en la reflexión sobre esos problemas compararemos, como ya hemos apuntado, la información de las cuentas de Sancho IV de 1292 con la del Becerro de las Behetrías de $1352^{6}$.

De los cuadernos de rentas de Sancho IV, en este trabajo vamos a centrarnos en El liuro de las rentas ciertas del año de la era de mil e CCC e XXX años referido a Castilla en 1292, que contiene información sobre la recaudación y los pagos de situados de las siguientes rentas: martiniegas y derechos, rentas de herrerías, tercias, almojarifazgos, rentas de salinas y heredamientos ${ }^{7}$. Y también analizaremos parcialmente el texto conocido como padrón de las aljamas o padrón de Huete que contiene los tributos de los judíos en 1290 y la distribución que se realizó en el ordenamiento de Toledo en $1291^{8}$.

En estas páginas limitaremos nuestro análisis a la zona cuya estructura señorial conocemos mejor por haberla estudiado en otros trabajos; se trata de la zona sur de Castilla la Vieja comprendida en las merindades de Burgos, Castrojeriz, Candemuño o Muñó y Santo Domingo de Silos ${ }^{9}$. Las rentas que

(1287-1289) y la conocida como "Nómina de la Frontera de Andalucía" (1290). Otros estudios de referencia para los objetivos de estas páginas sobre esos textos, en Vázquez 2004; o Sánchez 2006. A esos libros de rentas hay que añadir otros cuadernos de cuentas también de Sancho IV que publicó en su día M. Gaibrois y después A. López Dapena, igualmente de gran interés, aunque contienen menos información para los objetivos que perseguimos en este artículo. Véase Gaibrois 1922-1928; y López 1984. Sobre el reinado de Sancho IV, también Nieto 1994

${ }^{6}$ Martínez 1981. Para el estudio del Becerro de las Behetrías y, por extensión, del poder señorial de los nobles en esos momentos es fundamental Estepa 2003.

${ }^{7}$ Eran las "rentas ciertas", que eran solo una parte de los ingresos de la monarquía; no incluían, claro está, los tributos extraordinarios, pero tampoco a otros de los que pudiéramos considerar ordinarios. Sobre ello, Hernández 1993, pp. LXXXI-LXXXII.

${ }^{8}$ El "padrón", "repartimiento" o "partición" de Huete es un texto bien conocido porque en él se contiene un listado de la aljamas judías castellanas y las cantidades que debían pagar cada una de ellas en el tributo o pecho de los judíos, que por entonces alcanzaba cantidades muy elevadas: casi dos millones de maravedís (Ladero 1993, pp. 78-84). Su estudio permite conocer la distribución de la población judía y la entidad de las distintas aljamas cuando se realizó en 1290. Pero a nosotros nos interesa aquí porque esas cantidades se distribuían como situados entre los nobles; el reparto se realizó el año siguiente, en 1291.

${ }^{9}$ En conjunto se trata de un territorio de casi $8.500 \mathrm{~km}^{2}$, que se extiende fundamentalmente por el centro y el sur de la actual provincia de Burgos, aunque también por pequeñas zonas de Palencia, Soria y La Rioja. La descripción y la extensión de las merindades mencionadas en Martínez 1981. Es un territorio suficientemente amplio, de manera que las conclusiones que podamos obtener, aunque provisionales, sí tendrán una cierta representatividad. Por otra parte, sobre él, tanto en lo que se refiere a los señoríos como a los situados, veremos proyectarse a los diferentes sectores de la nobleza, de modo que también en este sentido las conclusiones resulta- 
encontramos en esa zona en el liuro de las rentas ciertas de 1292 y, por consiguiente, aquellas en las que centraremos nuestro análisis son las martiniegas y derechos, los heredamientos y las tercias, puesto que en la zona no había rentas de salinas o herrerías ni almojarifazgos. Además, estudiaremos también los tributos de los judíos de las aljamas de la zona en 1291 .

Desarrollaremos nuestro análisis en dos campos: por un lado, el de los beneficiarios de los situados y, por otro lado, las formas señoriales. En relación con lo primero realizaremos un análisis global de los beneficiarios de situados en la zona y en las rentas indicadas en 1291-1292. Para lo segundo estudiaremos la relación entre los situados y los tipos de señoríos, para lo que nos centraremos en los situados de 1292 adscritos sobre villas individuales, puesto que nos permitirá la comparación más sencilla con la información señorial del Becerro de las Behetrías en 1352. Son fundamentales las aportaciones realizadas en varios trabajos por Carlos Estepa, que son claves para conocer la estructura señorial y la composición y estratificación de la nobleza, elementos básicos en nuestro análisis ${ }^{10}$.

Los distritos fiscales para la recaudación de las martiniegas y los derechos, así como los heredamientos eran las merindades. Como consideración previa, hay que tener en cuenta que la geografía administrativa y fiscal no era igual en 1292 y 1352. Si en 1352 la zona se articulaba en torno a las merindades de Burgos, Castrojeriz, Muñó y Silos, en 1292 la merindad de Muñó se dividía en dos, puesto que Lerma y el Infantado de Covarrubias formaban una merindad independiente. Al estudio de esas y otras diferencias hemos dedicado un trabajo reciente, al que remitimos para más detalle sobre esos aspectos ${ }^{11}$.

Por lo que se refiere a las tercias, se recaudaban por obispados y, dentro de estos, a partir de los arciprestazgos; y los tributos de los judíos también por obispados, pero a partir de las distintas juderías ${ }^{12}$. Nos referiremos, entonces, a los situados sobre las tercias del obispado de Burgos de los arciprestazgos incluidos en las merindades de Burgos, Castrojeriz, Muñó y Silos; y haremos lo mismo con las juderías de esas mismas merindades ${ }^{13}$. En su

rán significativas. Por último, téngase en cuenta asimismo que el territorio se articula en torno a Burgos, uno de los núcleos centrales del poder regio.

${ }^{10}$ Sus trabajos son numerosos, pero para estas páginas son imprescindibles Estepa 1994 y su monumental Estepa 2003.

${ }^{11}$ Álvarez en prensa

${ }^{12}$ Hay algunas excepciones en lo que se refiere a las tercias, puesto que se mencionan las de algunos lugares concretos dentro de los arciprestazgos y sus correspondientes situados; pero son pocos casos y poco significativos. Hernández 1993, pp. 95, 96, 101 y 102.

${ }^{13}$ Son los arciprestazgos de Burgos, Villasandino, Palenzuela y Lerma con el Infantado de Covarrubias, Castrojeriz, Villahoz, Muñó, Mazariegos, Río Úrbel, Rio Ubierna, Lara y Cinco Villas con la abadía de San Quirce, y las tercias de Barruelo y San Andrés de Ibeas, (en las tercias del arciprestazgo de San Pedro del Campo, en la merindad de Castrojeriz, no figura ningún 
edición de las rentas de Sancho IV Hernández incorporó numerosos mapas que facilitan la tarea. Puede haber pequeños desajustes en la geografía fiscal de las tres rentas estudiadas (martiniegas, tercias y tributos de judíos), pero serán pequeñas y no impedirán una visión general, como la que pretendemos aquí.

\section{LOS BENEFICIARIOS DE SITUADOS EN 1292}

En el conjunto de las rentas y de las zonas estudiadas 69 beneficiarios distintos se repartían un total de 283.648 maravedís. Resumimos los datos en la Tabla 1, pero las cifras merecen algunos comentarios ${ }^{14}$.

En cuanto a las rentas, destaca muy por encima de las demás el pecho de los judíos de Burgos. La cifra, muy elevada, nos habla en primer lugar del peso demográfico de la judería de Burgos (y de las otras aljamas de la zona incluidas en ella a efectos fiscales); pero también nos habla de la enorme presión fiscal que soportaban los judíos. También las tercias, como es sabido, suponían cantidades muy significativas. Lógicamente, las rentas más voluminosas soportaban el mayor número de beneficiarios: el ya mencionado pecho de los judíos de Burgos, las tercias de los arciprestazgos de la zona y las martiniegas, derechos y heredamientos de las merindades de Castrojeriz y de Burgos.

Enseguida veremos quiénes eran los 69 beneficiarios de situados y su condición social. Para el análisis proponemos clasificarlos en cinco grupos, como se muestra en la Tabla 2: eclesiásticos, ricoshombres y familia real, caballeros, oficiales y criados.

Antes de adentrarnos en ello, las cifras necesitan algunas precisiones sobre los criterios empleados, porque los números que ofrecemos son menos seguros de lo que parecen. En primer lugar, hemos contabilizado como un beneficiario los casos en que se trata de dos personas, hermanos siempre, que disfrutan conjuntamente del mismo situado. El caso más frecuente es el de Muño y Pedro Díaz de Castañeda, que siempre aparecen juntos y que fueron ambos almirantes de Castilla entre 1286 y 1291. También Pedro y Rodrigo Álvarez, hijos de Pedro Álvarez (de Asturias), y Juan y Pedro González, hijos de Gonzalo Gómez de Sandoval.

situado; ibidem, p. 100). En cuanto a las juderías, son las de Burgos, de Castrillo y de Lerma, Muñó y Palenzuela.

${ }^{14}$ Para la valoración de las cifras, téngase en cuenta que las cantidades que figuran en las rentas estudiadas lo eran de maravedís "de la guerra", cuyo valor multiplicaba por seis veces el de la "moneda nueva". Sobre las monedas utilizadas en las rentas de Sancho IV y sus equivalencias ibidem, pp. CXCI-CIC. 
Por otro lado, la adscripción de algunos personajes a uno u otro grupo es dudosa en algunas ocasiones. De algunos dudamos si eran caballeros o ricoshombres y en el grupo de los ricoshombres hemos incluido también a los miembros de la familia regia. También hemos dudado en algunos casos si incluir a ciertos individuos en el grupo de los caballeros o en el de los oficiales e incluso en el de los criados. Por ejemplo, hemos considerado como criado a Fernán Falcón y como caballero a Esteban Rangel a partir de otros datos incluidos en estas rentas, o en las rentas publicadas por Gaibrois y Dapena, o en los documentos de Sancho IV. Algo parecido cabe decir de algunos eclesiásticos, como el arcipreste de Astudillo, Fernán Castillo, que probablemente era criado u oficial de la reina, señora de Astudillo.

En cuanto a las cantidades, hay que tener en cuenta que en no pocas ocasiones en las rentas se recogió la existencia de un situado y el nombre de su beneficiario, pero no la cantidad asignada que, por lo tanto, resulta desconocida; de manera que las cifras totales también arrojan alguna distorsión.

En definitiva, los números son menos seguros de lo que pudiera parecer y no pretenden ser concluyentes. Sin embargo, con un carácter aproximado y con todos los matices necesarios, sí tienen la virtud de ofrecernos un panorama de la situación que permite avanzar en el análisis y trazar algunas conclusiones, aunque sean provisionales.

Con esos matices podemos adentrarnos en el estudio un poco más detallado de las cifras.

La gran mayoría de los beneficiarios y de las cantidades asignadas corresponden a los ricoshombres y los caballeros. Ambos suman 50 de los 69 beneficiarios que hemos contabilizado, esto es, el 72,46\%, y en conjunto recibían 253.379 maravedís de los 283.648 asignados, esto es, el 89,32\%. Puede que algunos de estos situados correspondan al pago de salarios por el ejercicio de oficios, pero en su mayoría correspondían al pago de cantidades a cambio de fidelidad; es decir, la recompensa vasallática ordinaria que en buena medida se concretaba en rentas. Claro que esa recompensa suponía también el vínculo militar, pero en el contexto de finales del siglo XIII y comienzos del XIV, además de procurar de efectivos al ejército regio, los situados eran la forma ordinaria que tenía el rey de obtener el apoyo de la nobleza.

Claramente, los más beneficiados eran los ricoshombres y los miembros de la familia real, algo que en absoluto puede sorprendernos. Siendo 20 beneficiarios, el 28,98\%, obtenían 181.863,5 maravedís, el 64,12\%. Los 30 caballeros que hemos contabilizado suponían el 43,47\% de los beneficiarios, pero obtenían una cuarta parte de las rentas asignadas $(25,21 \%)$. La cantidad media que recibían los ricoshombres era también mucho más elevada, 9.093,18 maravedís frente a los 2.383,85 de los caballeros, cifra similar a la media de los situados de los oficiales (2.300,82 maravedís), 
mientras que los eclesiásticos y los criados recibían cantidades mucho más reducidas; aunque cuando se trata de un número pequeño de beneficiarios las cifras pierden representatividad por los casos de los situados sobre cantidades desconocidas, no especificadas en el libro de las rentas.

Pero si estas cifras nos ofrecen un panorama global de los tipos de beneficiarios, un análisis más detallado nos permitirá añadir algunos matices en cada uno de los sectores.

\subsection{Eclesiásticos, criados y oficiales regios}

Entre los eclesiásticos la cantidad más importante recogida en las rentas son 3.000 maravedís del monasterio de Silos como heredamiento, que en realidad corresponden a una donación anterior de Alfonso $\mathrm{X}^{15}$. El mencionado arcipreste de Astudillo disponía de 300 maravedís en Dehesilla de Astudillo porque se los habían dado el rey y la reina ${ }^{16}$. Otros beneficiarios eclesiásticos de situados como la iglesia de San Pedro de Burgos, el monasterio de San Cristóbal de Ibeas de Juarros o la priora del monasterio de Santa María de Brazacorta Urraca Álvarez (y esta última ¿a título individual? ¿en su calidad de priora?) disfrutaban de cantidades desconocidas ${ }^{17}$.

Los criados que hemos contabilizado eran tres personas, pero una recibía dos situados. La moza de cámara de la reina Aldonza López recibía en Encío en calidad de heredamiento 60 maravedís, que se sumaban a una cantidad indeterminada sobre las tercias también de Encío y de Tormantos. Mari Gutiérrez, ama de la reina, tenía en Villatuelda como heredamiento todos los pechos e los derechos e los seruicios, aunque no se señala a qué cantidad ascendían. Y Fernán Falcón (también mencionado) disponía de 1.600 maravedís en el pecho de los judíos de Burgos ${ }^{18}$.

Hemos contabilizado un total de 11 oficiales regios como beneficiarios de las rentas que hemos estudiado. En conjunto, la cantidad total que hemos podido registrar ascendía a 25.309 maravedís, pero había otras canti-

${ }^{15}$ Ibidem, p. 27. La donación regia que se evoca ha de ser la de la martiniega en 1256; véase Vivancos 1995, doc. 205.

${ }^{16}$ Hernández 1993, p. 29.

${ }^{17}$ Ibidem, pp. 27, 95 y 101.

${ }^{18}$ Ibidem, pp. 33, 102, 27 y 148. Además, Fernán Falcón disponía de otros 1.600 maravedís en las juderías de Toro y de Badajoz; ibidem, pp. 345.362, 369, 379 y 387 . Y aunque en estas rentas de 1292 figura entre los vasallos del infante Fernando en otros fragmentos de rentas de 1294 figura al servicio del rey, por lo que recibía una quitación o soldada mensual de 150 maravedís, además de algunos paños para vestido (siete varas de paño tinto para tabardo); Gaibrois 1922-1928, t. 1, pp. LXXIV, CXXIX, CXXXI y CXLVII. 
dades que no se especifican en el libro de rentas. Varios de esos situados estaban establecidos sobre rentas de villas individuales y nos referiremos a ellos más adelante: los 3.000 maravedís de Fernán Pérez, canciller de la reina, en Ciadoncha como heredamiento; 60 maravedís de Juan Pérez de Carrión en Villayuda también como heredamiento; o 42, correspondientes a siete cargas de pan, de Alfonso Pérez de la Cámara en Grijalba. Además, el camarero del rey, Juan Mathé, tenía los derechos de Ruyales y Mecerreyes asimismo como heredamiento. Era una cantidad sin especificar que se sumaba a otra, igualmente desconocida, por las tercias de esos mismos lugares ${ }^{19}$. Juan Mathé era un oficial importante y las que mencionamos eran solo una pequeña parte de las cantidades que tenía asignadas en otras rentas de otras zonas. También Fernán Pérez Maimón era otro oficial importante y en este caso su posición sí se refleja en el situado de 3.000 maravedís que recibía en Ciadoncha. Mientras que el merino mayor de León Pedro Fernández Cabeza de Vaca tenía 180 maravedís en Villamayor (de Treviño); los había tenido por heredamiento y ahora los tenía por tierra ${ }^{20}$.

Otros altos oficiales también disfrutaban de situados en las rentas que hemos estudiado. Así, García López de Saavedra, mayordomo del rey por el mayordomo mayor Ruy Pérez Ponce, maestre de Calatrava, obtenía 1.411 maravedís en el pecho de los judíos de Burgos ${ }^{21}$. Juan Alfonso de Arenillas era repostero mayor del rey y en esta zona considero que disfrutaba de dos situados por un valor total de 4.800 maravedís ${ }^{22}$. Sancho Martínez de Leiva, merino mayor de Castilla durante buena parte del reinado de Sancho IV, entre 1284 y 1292, tenía otros importantes situados en otras zonas, pero en las que estudiamos disponía de 1.200 maravedís en la martiniega de Río Ubierna ${ }^{23}$. Pero era el Justicia Mayor de la Casa del Rey, Tello Gutiérrez, el que obtenía una cantidad mayor: un total de 8.616 maravedís en dos situados, uno de 2.616 maravedís en el pecho de los judíos de Burgos y otro de 6.000 en las tercias

${ }^{19}$ Ibidem, pp. 28, 30 33, 34 y 96. Véase Tabla 4.

${ }^{20}$ Ibidem, p. 30

${ }^{21}$ Ibidem, p. 148.

${ }^{22}$ Cada uno de los dos situados que le atribuimos era de 2.400 maravedís. Bien identificado, con el apellido Arenillas se le menciona con un situado en las tercias del arciprestazgo de Mazariegos en el obispado de Burgos; sin el apellido Arenillas se menciona a un Juan Alfonso en la martiniega y derechos de la merindad de Castrojeriz. Este otro situado puede corresponder a algún otro de los homónimos que figuran en las rentas de Sancho IV, incluyendo al ricohombre Juan Alfonso de Haro, que también tenía un situado en la zona; pero lo hemos atribuido a Juan Alfonso de Arenillas por la proximidad a la zona donde nucleaban sus dominios los Arenillas. Sin embargo, hay que tener en cuenta que esa identificación es hipotética. Ibidem, pp. 29 y 87. Sobre este personaje, véase Gaibrois 1922-1928, t. 1, p. 41; t. 2, p. 253 y t. 3, doc. 201 . Y sobre los Arenillas Estepa 2003, t.1, pp. 405-406.

${ }^{23}$ Ibidem, p. 32. 
del arciprestazgo de Palenzuela, Lerma y el Infantado ${ }^{24}$. Por último, las rentas también recogen una asignación de 3.000 maravedís para el merino en los derechos del conjunto de la merindad de Burgos. Una cantidad que parece corresponder al salario, creemos que del merino menor, aunque no podemos asegurar que no se refiera al merino mayor, pero que no se había recaudado (minguan, dice el texto) por una donación relacionada con el portazgo que había hecho el rey a los de Santander y a los de Aguilar ${ }^{25}$.

\subsection{Caballeros}

Los caballeros suponen menos de la mitad de los beneficiarios de situados en las rentas que hemos estudiado. Eran 30 individuos (recuérdese lo dicho sobre los situados de hermanos) y la mayoría de ellos tenían un único situado, lo que será una de las diferencias respecto a los ricoshombres, como veremos. Bastantes de ellos son conocidos, al menos en sus apellidos identificadores, lo que nos permite situarlos en un determinado contexto familiar, e integraban los distintos niveles de la nobleza media y de la baja nobleza.

Por el número de sus miembros que recibían situados, las familias o grupos familiares más beneficiados en las rentas que hemos estudiado eran los Sandoval, los Padilla, los Lucio, los Baztán y los de la Vega. Son grupos familiares que, excepto los Baztán, dispondrán también de derechos señoriales en la zona a mediados del siglo XIV según el Becerro de las Behetrías. Destacan en primer lugar los Sandoval, un grupo familiar amplio, con varias ramas, todavía mal conocido, aunque uno de ellos, Juan Rodríguez de Sandoval era un poderoso señor de behetrías y fue clave en las disputas sobre ellas a mediados del siglo XIV ${ }^{26}$. Los Sandoval que disponen de situados en las rentas de Sancho IV son: Diego Gómez, Gutierre Díaz y su hijo Gómez Gutiérrez, Juan González y Pedro González (ambos conjuntamente) hijos de Gonzalo Gómez, y Ruy Gutiérrez que disfruta de un situado que antes había tenido su hermano Ruy González. En las rentas que estudiamos, destacan sus situados en la merindad de Castrojeriz, vecina de la de Villadiego y zona donde sus dominios eran más intensos ${ }^{27}$.

Por lo que se refiere a los Padilla, tres de ellos disponían de situados en las rentas que estudiamos: Diego García de Padilla, que tenía un

\footnotetext{
${ }^{24}$ Ibidem, pp. 148 y 96.

${ }^{25}$ Ibidem, p. 33.

${ }^{26}$ Sobre los Sandoval, Estepa 2003, pp. 396-401 y Cuadro VII en p. 438 sobre los señoríos de Juan Rodríguez de Sandoval. También Gaibrois 1922-1928, t. 2, pp. 334-335.

${ }^{27}$ Hernández 1993, pp. 26, 29, 30 y 148.
} 
situado que antes había tenido su pariente Fernán García de Padilla; también Juan García, sobrino de Diego García; pero, sobre todo, destaca Pedro López de Padilla por el valor de sus rentas que ascendían a 8.100 maravedís. Pedro López ocupó después cargos importantes en el reinado de Fernando IV. En las rentas estudiadas, todas las de los Padilla estaban situadas en la martiniega y derechos de la merindad de Castrojeriz, zona nuclear de sus dominios $^{28}$.

Aunque no podemos asegurarlo por completo, creemos que los personajes que en las rentas de 1292 figuran como los Luçion corresponden a la familia que después lleva el apellido Lucio, en referencia al valle de Valdelucio al noroeste de la provincia de Burgos. A mediados del siglo XIV los Lucio y los Villegas formaban parte del mismo grupo familiar ${ }^{29}$. En el pecho de los judíos de Burgos tenían sendos situados Pedro Fernández y Juan Fernández de Luçion, que probablemente eran hermanos ${ }^{30}$. Si nuestra identificación Lución/Lucio es correcta y en estos momentos de finales del siglo XIII los Lucio y los Villegas estaban ya relacionado, tendríamos que incluir en este grupo familiar también a Alfonso Pérez de Villegas, que tenía un pequeño situado de 90 maravedís como heredamiento en Villamorón en la merindad de Castrojeriz ${ }^{31}$.

En cuanto a los de la Vega, nucleaban sus propiedades más al norte, en Asturias de Santillana, pero dos de ellos tenían también situados en las rentas que estudiamos en el pecho de los judíos de Burgos: Alfonso Ruiz y Pedro Ruiz de la Vega, que probablemente eran hermanos ${ }^{32}$.

Tampoco los Baztán eran nobles de la zona. Procedentes de Navarra, se documentan sus intereses en la Rioja y más tarde figuran vinculados a los Haro de Cameros. En las rentas de Sancho IV en esta zona Juan Fernández de Baztán "el Menor" tenía un situado y dos Juan González de Baztán, uno de ellos que antes tenía su padre llamado igualmente Juan Fernández de Baztán y apodado "el Mayor"333. Seguramente Juan González y Juan Fernández "el Menor" eran hermanos y ambos eran hijos de Juan Fernández "el Mayor". El primero de ellos, Juan González, era el más poderoso; en la zona que estudiamos todos sus situados estaban en el pecho de los judíos de Burgos, pero Juan González tenía otros más cuantiosos en las juderías de Calahorra y

\footnotetext{
${ }^{28}$ Ibidem, p. 30; y sobre los Padilla Estepa 2003, pp. 401-404.

${ }^{29} \mathrm{El}$ editor de las rentas considera que apellido era "Lución", pero nos inclinamos a pensar que era "Lucios/Lucio". Los vínculos entre los Lucio y los Villegas y su proyección señorial en Estepa 2003, pp. 411-414.

${ }^{30}$ Hernández 1993, p. 148.

${ }^{31}$ Ibidem, p. 31.

${ }^{32}$ Ibidem, p. 148; y Estepa 2003, pp. 416-422.

${ }^{33}$ Hernández 1993,p. 148.
} 
Logroño, zonas donde, como apuntamos, se documentan sus intereses patrimoniales y su actuación política ${ }^{34}$.

Otros caballeros miembros de familias cuyos intereses señoriales están bien documentados en la zona a través del Becerro de las Behetrías constan asimismo disfrutando de situados en las rentas de Sancho IV. Así, García García de Herrera, Lope Alfonso de Torquemada, Sancho de Velasco o Ruy González de Villamayor ${ }^{35}$. Y también otros cuyos dominios se centraban en otras zonas, como Pedro Bravo de Argomedo, Gonzalo Gómez o González, hijo de Gonzalo Ruiz de Atienza, Sancho Sánchez Ladrón, Lope de Mendoza o Alfonso López de Saavedra ${ }^{36}$. Algunos de estos últimos estaban, en realidad, entre los mayores beneficiados de situados de la zona dentro del grupo de los caballeros, lo que resulta llamativo. También figuran en las rentas como beneficiarios de situados otros personajes que hemos incluido en el grupo de los caballeros, pero que no hemos podido identificar, bien por carecer de apellidos identificadores (Esteban Rangel, Payo González), bien porque seguramente tenían una proyección menor que los citados más arriba (Esteban Eanes d'Anchos, Ruy Gutiérrez de Zurita, Juan Gutiérrez de Villataud o Ruy Díaz de Villodrigo). Nos parece significativo señalar que sus situados estuvieran en todos los casos en el pecho de los judíos de Burgos ${ }^{37}$.

Pero, como hemos apuntado, la mayor proyección señorial en la zona, tal como la podemos apreciar unos años más tarde en el Becerro de las Behetrías, no siempre se correspondía con los mayores beneficiarios de situados en las rentas de Sancho IV. Sí vemos esa equivalencia en el caso de Pedro López de Padilla, el caballero que obtenía en total una suma más alta en las rentas que hemos estudiado, puesto que tenía dos situados por un valor total de 8.100 maravedís $^{38}$. También algunos Sandoval, como Diego Gómez, a quien atribuimos otros dos situados por un total de 4.340 maravedís $^{39}$; o Juan

${ }^{34}$ Ibidem, pp. 43, 46, 152 y 156. Su proyección en la Rioja, por ejemplo, en Álvarez 2019 y al servicio de Sancho IV también en Gaibrois 1922-1928, t. 2, pp. 69-70.

${ }^{35}$ Hernández 1993, pp. 148-150. Sobre estas familias y algunos de los personajes mencionados Estepa 2003, t. 1, pp. 380-386 y 406-408, y t. 2, pp. 7-10. Algunos Villamayor pertenecían a la alta nobleza y eran ricoshombres, pero creemos que no lo era Ruy González, por lo que le hemos incluido en el grupo de los caballeros, aunque con algunas dudas.

${ }^{36}$ Hernández 1993, pp. 26, 30, 32, 95, 98 y 148. En las rentas figuran Gonzalo Gómez y Gonzalo González, en ambos casos como hijos de Gonzalo Ruiz de Atienza; sin tener plena certeza, creemos que no se trata de dos personajes hermanos, sino de uno solo, cuyo apellido Gómez o González pudo haberse transcrito o leído mal.

${ }^{37}$ Ibidem, p. 148.

${ }^{38}$ Ibidem, p. 30.

${ }^{39}$ Un situado de 2.700 maravedís en la martiniega y derechos de la merindad de Castrojeriz, en el que figura bien identificado con el apellido Sandoval; y otro de 1.640 maravedís en la martiniega y derechos de la merindad de Silos, donde aparece solo como Diego Gómez. 
González y Pedro González, los hijos de Gonzalo Gómez de Sandoval (¿hermano del anterior?) con un situado de 3.600 maravedís $^{40}$; o también Lope Alfonso de Torquemada, con otro por valor de 3.657 maravedís ${ }^{41}$. Todos ellos tenían situados por encima de 3.000 maravedís; pero a su lado, también disponiendo de cantidades elevadas, encontramos a otros que, hasta donde sabemos, no tenían proyección señorial destacable en la zona. Como Payo González, que tenía 7.320 maravedís en el pecho de los judíos de Burgos, Juan González de Baztán con un total de 6.273,5, Gonzalo Gómez (o González) de Atienza con 4.430, Lope de Mendoza 3.700, o Sancho Sánchez Ladrón y Pedro Bravo de Argomedo ambos con 3.00042. Y por debajo de ellos se van situando el resto. Merece la pena señalar que la mayoría disponían de más de 1.000 maravedís; por debajo de esa cantidad solo hallamos siete de los 30 caballeros con situados en la zona. Y también merece la pena destacar que la cifra de 1.000 maravedís es la más frecuente, con seis caballeros disponiendo de esa cantidad, lo que nos sugiere un pago estandarizado, quizás correspondiente o similar a una soldada.

\subsection{Ricoshombres y familia real}

Por último, el grupo que con diferencia obtenía un mayor volumen de rentas eran los ricoshombres y los miembros de la familia real. Los 20 individuos de este grupo que hemos identificado recibían casi el $65 \%$ de todas las rentas situadas. Recibían más cantidades, la media de lo que obtenían era muy superior a los otros grupos y la mayoría disfrutaban de más de un situado.

En primer lugar, hay que señalar que, como ya hemos indicado más arriba, en este grupo hemos incluido a los infantes y a la propia reina María de Molina. La reina tenía dos importantes situados en las martiniegas y los derechos de Astudillo, en la merindad de Castrojeriz, y de Muñó y Villavieja, en la de Candemuño, por un total de 9.415 maravedís ${ }^{43}$. En cuanto a los infantes, conviene diferenciar dos conceptos: por un lado, rentas asignadas a cada uno de ellos de manera, diríamos, particular; y, por otro lado, cantidades redistribuidas a sus vasallos. Al segundo aspecto nos referiremos más adelante, sobre

Creemos que se trata de la misma persona, pero no podemos asegurarlo por completo. Ibidem, pp. 26 y 29.

${ }^{40}$ Ibidem, p. 30.

${ }^{41}$ Ibidem, pp. 149-150.

${ }^{42}$ Los situados de Payo González y Juan González de Baztán en ibidem, p. 148 y 149; Gonzalo Gómez de Atienza en ibidem, pp. 30, 32 y 95; Lope de Mendoza en ibidem, p. 26; Sancho Sánchez Ladrón en ibidem, p. 98 y Pedro Bravo de Argomedo en ibidem, p. 32.

${ }^{43}$ Ibidem, pp. 28 y 29. 
todo por las elevadas rentas asignadas a los vasallos del infante Fernando. Pero centrándonos ahora en lo primero, encontramos situados a favor de los hijos de Sancho IV, los infantes Alfonso y Pedro, no así del infante Fernando, que no tenía situados directos en las rentas que hemos estudiado. El infante Alfonso tenía un situado de 1.649 maravedís en el pecho de los judíos de Burgos; pero el infante Pedro acumulaba nada menos que 17.996 maravedís por tres situados en el cillero de Castrojeriz y en Olmillos de Sasamón, en los derechos de Lerma y en las tercias del arciprestazgo de Palenzuela, Lerma y el Infantado de Covarrubias ${ }^{44}$. También encontramos a la infanta Blanca, con un situado de 3.000 maravedís en la martiniega de Clunia. Se trata de la infanta Blanca de Portugal que unos años más tarde se convertiría en señora del poderoso monasterio de Las Huelgas de Burgos. Era hija de Alfonso III de Portugal y Beatriz de Castilla, y esta última, a su vez, hija ilegítima de Alfonso $\mathrm{X}^{45}$. También encontramos a otros parientes del rey, como Juan Manuel, hijo del infante Manuel y primo de Sancho IV. Sus situados en la zona sumaban un total de 26.220 maravedís, 20.000 en el pecho de los judíos de Burgos y 6.220 en la martiniega y derechos de la merindad de $\operatorname{Silos}^{46}$. También podemos incluir en ese grupo a Alfonso de Molina, hermano de la reina, nieto de Alfonso IX de León, cuyos situados en la zona ascendían a un total de 9.895,5 maravedís ${ }^{47}$. Otro descendiente, en este caso por vía ilegítima, de Alfonso IX y pariente lejano de Sancho IV era Juan Fernández, apodado Cabellos de Oro, que tenía un situado de 5.610 maravedís en el pecho de los judíos de Burgos ${ }^{48}$. Juan Fernández y Alfonso de Molina ocupaban los principales oficios de la corte, el primero era mayordomo mayor y el segundo alférez, pero hemos primado su condición de ricoshombres y por ello los hemos incluido en este apartado.

Entre los restantes ricoshombres encontramos a miembros de las familias y grupos familiares que dispondrán de derechos señoriales en la zona, tal y como se atestigua después en el Becerro de las Behetrías; pero llama la atención que también encontramos a otros que no cumplen esa condición y además entre los beneficiarios de las cantidades más elevadas. Así, Pedro Álvarez y Rodrigo Álvarez, hijos de Pedro Álvarez de Asturias eran quienes obtenían la cantidad más alta, 27.876 maravedís en el pecho de los judíos de Burgos $^{49}$. Radicando sus dominios y señoríos en otras zonas, llama la aten-

${ }^{44}$ Ibidem, pp. 149, 49, 34 y 96, por el orden que las hemos mencionado. El infante Alfonso debió morir a finales de 1291 y el reparto del tributo de los judíos (el ordenamiento de Toledo) se hizo en febrero de ese año.

${ }^{45}$ Ibidem, p. 27. Sobre la infanta Blanca de Portugal Reglero 2016.

${ }^{46}$ Hernández 1993, pp. 147 y 26.

${ }^{47}$ Ibidem, t. 1, pp. 26, 30, 97 y 148.

${ }^{48}$ Ibidem, t. 1, p. 148.

${ }^{49}$ Ibidem, t. 1, pp. 147-148. 
ción una cantidad tan elevada en estas rentas. Quizás se deba a que su madre era una Lara, Sancha Rodríguez ${ }^{50}$. No conocemos su relación con Arias Díaz de Asturias, quien también tenía varios importantes situados en la zona que sumaban un total de 12.541 maravedís, aunque de este último sí se conoce una donación de Sancho IV en zonas próximas ${ }^{51}$.

También eran muy importantes los situados de Pedro y Muño Díaz de Castañeda, quienes, como ya se ha indicado, siempre se mencionan conjuntamente en las rentas estudiadas y que habían sido también conjuntamente almirantes de Castilla hasta 1291; también en su caso hemos primado su condición de ricoshombres, antes que oficiales, para incluirlos en este apartado. En este caso, sí se trata de nobles arraigados en la zona y algunas de las rentas las recibían en calidad de heredamiento. En total sus situados ascendían a 21.270 con cantidades importantes en las tercias del obispado de Burgos ${ }^{52}$. También Fernán Pérez de Guzmán acumulaba varios situados que en total ascendían a 9.668 maravedís ${ }^{53}$.

Si la cantidad media de los situados de los ricoshombres en la zona que estudiamos era de algo más de 9.000 maravedís, por debajo de esa cifra encontramos todavía otras cantidades elevadas, como los 8.400 maravedís en martiniegas (y portazgo) de la merindad de Burgos de Juan Alfonso de Haro o los 8.165 que tenía por su padre en el pecho de los judíos de Burgos Fernán Rodríguez de Castro ${ }^{54}$. Llama la atención que en la lista de los nobles más beneficiados por situados en la zona, los Lara no figuren en los primeros lugares. En las rentas que estudiamos solo figura Juan Núñez conocido como "el Mozo" con 6.000 maravedís en las tercias de Burgos, en un situado que, según las rentas, tenía el deán de Sevilla y que estaba asignado, seguramente de forma temporal, al infante Pedro ${ }^{55}$. La cantidad relativamente reducida y la asignación temporal al infante seguramente remitan al apartamiento de la corte y los enfrentamientos intermitentes con el rey.

García Fernández de Villamayor y Juan García de Villamayor eran ricoshombres (a diferencia de su pariente Ruy González de Villamayor, a quien hemos considerado caballero). El primero disfrutaba de un total de cinco situados en las martiniegas y derechos de las merindades de Burgos,

\footnotetext{
${ }^{50}$ Moxó 1969,p. 144.

${ }^{51}$ Hernández 1993, pp. 32, 98, 149 y 150.

${ }^{52}$ Ibidem, pp. 28, 95, 96, 97 y 129.

${ }^{53}$ Ibidem, pp. 26 y $98-99$.

${ }^{54}$ Ibidem, pp. 32 y 148. Ni uno ni otro tendrían tampoco señoríos destacados en la zona según el Becerro de las Behetrías.

${ }^{55}$ Ibidem, p. 95.
} 
Muñó y Castrojeriz que sumaban un total de 4.640 maravedís; el segundo tenía dos en las merindades de Burgos y Lerma que sumaban 3.000 maravedís $^{56}$. Y, como los Villamayor, los Manrique, los Villalobos o los Aza eran familias o grupos familiares ligados a la ricahombría y con propiedades y derechos en la zona. Rodrigo Álvarez de Aza tenía 300 maravedís como heredamiento en Villaquirán, en la merindad de Muñó, y otros 3.418 maravedís en el pecho de los judíos de Burgos ${ }^{57}$. Lope Rodríguez de Villalobos un total de 1.800 maravedís en las martiniegas y derechos de Hormaza en la merindad de Castrojeriz y de Ubierna en la de Burgos con Ubierna ${ }^{58}$. Mientras que Gómez Manrique tenía 1.000 maravedís también en el pecho de los judíos de Burgos y su pariente García Fernández Manrique otro situado por cantidad no especificada por heredamiento en Vivar del Cid en la merindad de Burgos ${ }^{59}$.

\subsection{Otros aspectos del pago de situados: pirámide vasallática y cambios en los pagos}

El libro de las rentas de 1292 todavía permite algunas otras consideraciones sobre los beneficiarios de los situados, a las que nos referiremos ahora de una forma breve. Una de ellas es que permite vislumbrar la conformación de la pirámide feudovasallática, aunque sea de una forma muy parcial, puesto que ofrece algunos ejemplos de cómo, en algunos casos, las cantidades se redistribuían de los nobles más poderosos hacia sus vasallos de nivel inferior. En el libro de las rentas se destaca especialmente el caso del infante Fernando, pero no es el único ${ }^{60}$.

Como se recoge en la Tabla 1, la renta más importante por su cuantía era el pecho de los judíos de Burgos. En él, como en los de otras juderías, las cantidades situadas se distribuían en dos grupos; por un lado, los vassallos del rey y, por otro lado, las cantidades al infante don Ferrando, para estos sus vassallos, de manera que se ofrecen dos listados, que nos permiten conocer la nómina de los vasallos de uno y otro. Sabemos así que los vasallos del infante eran numerosos y que las cantidades que recibían eran elevadas: la mitad aproximadamente del pecho de los judíos de Burgos (59.186 maravedís), la

\footnotetext{
${ }^{56}$ Ibidem, pp. 28, 30, 32, 34 .

${ }^{57}$ Ibidem, pp. 28 y 150.

${ }^{58}$ Ibidem, pp. 29 y 32.

${ }^{59}$ Ibidem, pp. 148 y 33. Sin embargo, no estamos seguro de que Gómez Manrique fuera ricohombre.

${ }^{60}$ Sobre estos aspectos, ibidem, pp. CXLIV-CXLV.
} 
mitad también aproximadamente del de los judíos de Lerma, Muñó y Palenzuela (4.561 maravedís) y todo el de los de Castrillo ${ }^{61}$.

Pero no solo es el pecho de los judíos el que nos informa de los vasallos del infante Fernando, también otras de las rentas que hemos estudiado recogen situados asignados a él nominalmente para sus vasallos: las martiniegas y derechos de las merindades de Burgos, Castrojeriz y Silos, y las tercias de los arciprestazgos de Burgos y de Río Úrbel; de manera que, entre unas y otras, probablemente la lista que se puede obtener es bastante completa.

Una reconstrucción total de la nómina de los vasallos del infante exigiría una revisión global de las rentas, pero a partir de las que hemos estudiado nosotros sí podemos señalar que entre ellos figuran algunos importantes ricoshombres, como don Juan Manuel, Lope Rodríguez de Villalobos, Juan Alfonso de Haro, Pedro y Rodrigo Álvarez de Asturias o Arias Díaz; y entre ellos también encontramos a miembros de familias o grupos familiares de caballeros de la nobleza regional castellana: Sandoval, Torquemada o Cabeza de Vaca ${ }^{62}$.

$\mathrm{El}$ asunto merece un estudio específico que escapa a los objetivos de estas páginas, pero nos parece que hay que situar la cuestión de los vasallos del infante Fernando en su contexto político, limitando de alguna manera su alcance. Nos referimos a la insegura posición del infante como heredero por la discutida legitimidad del matrimonio de Sancho IV y María de Molina. Se pretendía, seguramente, reforzar la posición del heredero, dotándole de un cuerpo nutrido de vasallos, pero hay que entenderlo como una parte de la política regia, no pensamos que formaran un colectivo político autónomo. Sería, más bien, una reorganización de los recursos políticos del rey.

Por otro lado, las rentas nos informan también de las clientelas vasalláticas de otros miembros de la familia regia. También el infante Enrique (hijo de Fernando III, tío de Sancho IV) tenía rentas asignadas en las tercias del arciprestazgo de Río Ubierna que se pagaban a Sancho Sánchez Ladrón ${ }^{63}$. Y fuera ya de las rentas que estudiamos aquí, pero en zonas próximas, constan también rentas asignadas a los vasallos del infante Alfonso, hijo también de Sancho IV, que murió a finales de $1291^{64}$.

Otro aspecto interesante del libro de las rentas es que, aunque fundamentalmente es un registro estático, que refleja la situación en el momento

${ }^{61}$ Ibidem, pp. 147, 149 y 150. El pecho de los judíos de Castrillo, que era más modesto (6.720 maravedís), estaba asignado en su totalidad a Arias Díaz; en esa entrada no se señala, pero consta también su condición de vasallo del infante.

${ }^{62}$ Vasallos que, en todo caso, se sumaban a los oficiales y los miembros de la "casa" del infante; véase Nieto 1994, pp. 74-75.

${ }^{63}$ Hernández 1993, p. 98.

${ }^{64}$ Por ejemplo, en el pecho de los judíos de Briviesca y en el de los de Medina de Pomar; ibidem, pp. 150 y 152 . 
en que se elaboró, también en alguna medida es un inventario dinámico, puesto que en algunos casos no se nos informa solo del beneficiario actual del situado, sino también del anterior.

Los textos que recogen los tributos de los judíos muestran los muy frecuentes cambios y reajustes en la recaudación y en los pagos; el dinamismo de la Hacienda regia, tanto en un sentido como en otro. En el caso de los judíos de León se conservan registros de ingresos y gastos de 1286, 1287, 1288 y 1289 materializados en los correspondientes ordenamientos. En esos años las cantidades totales se fueron reduciendo y sería del mayor interés analizar cómo variaron los situados en esas rentas en paralelo a su reducción ${ }^{65}$. En Castilla, la llamada partición de Huete de 1290, en la que se fijaron las cantidades a pagar por las distintas aljamas, se concretó el año siguiente en el ordenamiento de Toledo en el que se establecieron los pagos de los situados para ese año a partir de lo dispuesto el anterior en Huete ${ }^{66}$. El texto que se conserva señala con bastante frecuencia pagos a distintos beneficiarios en los que se añadieron las expresiones quel pussieron en este ordenamiento o quel pussieron en el ordenamiento de Toledo; es decir, registra novedades y cambios en los pagos realizados conforme al ordenamiento de Toledo de 1291 respecto a otros ordenamientos anteriores que no conocemos.

En esos casos solo sabemos que son pagos nuevos o que han cambiado, pero otras veces las rentas sí nos detallan la situación anterior. La casuística es variada, pero pueden destacarse varios ejemplos significativos. En primer lugar, los situados que habían tenido nobles que ahora han perdido, por unas u otras razones, su posición en la corte, como los Haro ${ }^{67}$. También hay cambios y reajustes en los situados de Juan Núñez "el Mozo" que seguramente tengan que ver con sus enfrentamientos con el rey ${ }^{68}$. En otros casos, las rentas nos muestran cómo los situados pasan de unos parientes a otros, de padres a hijos, por ejemplo, o entre hermanos ${ }^{69}$. Y las rentas muestran también otros casos de cambios y reajustes en los situados, sin que se haga explícita la relación entre los beneficiarios anteriores y los actuales y sin que nosotros, a falta de un estudio sistemático, podamos aventurarla ${ }^{70}$.

${ }^{65}$ Ibidem, t. 1, pp. CXXXIII-CXLIV, especialmente el cuadro en p. CXL. Los textos en pp. 337-381.

66 "Desta guisa son partidos los mr que an a dar las aljamas de Castiella, segunt la partiçion de Huepte, a los ricos omnes e a los caualleros e a los otros que fincaron en el ordenamiento de Toledo por vn año, que començo por el febrero de la era de mill e cc (sic) xxix años". Ibidem, pp. 142 y ss.

${ }^{67}$ Ibidem, pp. 32, 33, 96 y 130.

${ }^{68}$ Ibidem, pp. 31, 34, 95 y 96.

${ }^{69}$ Ibidem, pp. 26, 30, 148 y 150

${ }^{70}$ Ibidem, pp. 26, 29, 148, 150 y 129. 


\section{SiTUADOS EN VILLAS Y SEÑORÍOS EN 1292 Y 1352}

En la segunda parte del artículo intentaremos analizar la relación entre los situados y la estructura señorial, esto es, las distintas formas señoriales existentes y sus titulares, de una manera más directa. Para ello compararemos la información disponible sobre villas concretas, individuales, en 1292 y 1352. Con ese fin, tendremos que limitar ahora el estudio solo a las martiniegas y derechos y los heredamientos, cuya recaudación se realizaba a partir de las merindades. En 1292 los nobles recibían situados adscritos a ellas de diversas maneras: sobre el conjunto de las martiniegas y derechos de una merindad, sobre las de determinados conjuntos de villas que remiten a distritos anteriores (alfoces, sayonazgos), sobre otros distritos y sobre villas individuales ${ }^{71}$. Para comparar la información con los datos del Becerro de las Behetrías de 1352 tendremos que centrarnos en los situados pagados sobre las rentas de villas individuales. Aunque son un número relativamente reducido, pensamos que el análisis es relevante.

En la Tabla 3 recogemos los datos del número de villas individuales sobre las que estaban asignados situados en 1292. Son un total de 27 lugares en las merindades estudiadas; de ellos, 24 figuran también en el Becerro de las Behetrías en 1352, de manera que pueden establecerse comparaciones interesantes. Hay que tener en cuenta que en el Becerro de las Behetrías no se incluyeron, por unas u otras razones, varios lugares, entre ellos algunos importantes como Aranda, Santo Domingo de Silos o la propia ciudad de Burgos ${ }^{72}$.

Es interesante señalar que el mayor número de lugares corresponde a behetrías, puesto que son ocho sobre los 24 lugares; es decir, un tercio. Pero son cifras que, en general, se corresponden bastante bien con los datos globales de la estructura señorial de la zona en $1352^{73}$. Podrían destacarse porcentajes más altos de realengos, pero tratándose de un número pequeño de lugares no creemos que sean datos significativos. En definitiva, no vemos que la estructura señorial determine la existencia, o no, de situados, puesto que estos se extendían por villas sujetas a todas las formas señoriales. Sin embargo, el número de casos estudiados aquí es pequeño, por lo que ha de considerarse esta idea más como una conclusión provisional que se debe con-

\footnotetext{
${ }^{71}$ Véase Álvarez en prensa.

${ }^{72}$ Sobre estos aspectos Álvarez en prensa.

${ }^{73} \mathrm{Hemos}$ hecho varios estudios sobre ello a partir de los cuales podemos ofrecer las siguientes cifras de la estructura señorial de las merindades de Burgos, Castrojeriz, Muñó y Silos en 1352. Total de lugares en esas merindades en el Becerro de las Behetrías, 469, de los cuales: realengos, $27=5,75 \%$; abadengos, $146=31,13 \%$; solariegos, $76=16,20 \%$; behetrías, $163=$ $34,75 \%$; condominios, $57=12,15 \%$. Véase Álvarez 1996a, 1996b. Y véanse también las cifras globales sobre todo el Becerro de las Behetrías en Estepa; Jular 2009 pp. 5-7.
} 
trastar todavía a partir de un análisis más amplio del libro de rentas de 1292, incluyendo todas las merindades, no solo las que hemos estudiado nosotros.

Merece la pena también detenerse en el análisis de los beneficiarios de los situados en 1292 en relación, de nuevo, con la situación señorial de los lugares en 1352.

\subsection{Abadengos}

En los abadengos, curiosamente, no encontramos mayoritariamente a los señores eclesiásticos de 1352 recibiendo situados en 1292. Solo lo vemos en un caso que no hemos incluido en la Tabla 3 , porque no se refiere a una villa individual, sino a un distrito; se trata de Silos donde el abad recibe un importante situado de 3.000 maravedís en su martiniega procedente de una donación de Alfonso $\mathrm{X}^{74}$. Interpretamos que no corresponde solo a la villa de Silos, sino al distrito formado también por sus aldeas dependientes. Por otro lado, también hay que tener en cuenta que pudo haber cambios en la titularidad del señorío de algunos lugares entre 1292 y 1352. No disponemos de todos los datos, pero fue el caso de Ciadoncha, que en 1352 pertenecía al monasterio de las Huelgas de Valladolid porque se lo había dado la reina María de Molina. No podemos asegurarlo, pero seguramente en 1292 era realengo $^{75}$.

Se puede destacar que las villas de abadengo concentraban la mayoría de los situados a favor de los oficiales y criados. En cinco de las siete villas que en 1352 eran abadengos y en 1292 tenían situados había beneficiarios que podemos identificar como oficiales o criados del rey o de la reina. Por otro lado, en las villas con situados en 1292 encontramos un total de siete oficiales o criados regios que obtenían situados en ocho villas, puesto que uno de ellos recibía rentas en dos lugares. Cinco de esas villas eran abadengos, otra solariego y dos behetrías (Tabla 4).

Claro que esos personajes eran muy diversos y entre ellos encontramos desde criados domésticos, como Mari Gutiérrez o Aldonza López, ama y couigera (moza de cámara) de la reina, hasta algunos altos oficiales como

\footnotetext{
${ }^{74}$ Hernández 1993, p. 27.

${ }^{75}$ Por otro lado, hay que tener en cuenta que Covarrubias tenía en 1352 formalmente la condición de realengo: "Este logar es del Rey que lo da al abat de Cuevas Ruuias"; Martínez 1981, XII-31.

Los otros lugares abadengos incluidos en la Tabla 3 eran Medinilla de la Dehesa, Encío y Villayuda en la merindad de Burgos; Jaramillo de la Fuente en la merindad de Silos; y Mecerreyes y Ruyales (además de Ciadoncha) en la merindad de Munó/Lerma. Tiene interés resaltar los casos de Ruyales y Mecerreyes, ambos del abad de Covarrubias, pertenecientes al Infantado y vinculados como heredamiento a Juan Mathé, camarero del rey; Hernández 1993, p. 34 y Martínez 1981, XII-33 y 35.
} 
el merino mayor de León Pedro Fernández Cabeza de Vaca, y Juan Mathé de Luna y Fernán Pérez Maimón, ambos altos oficiales y consejeros del rey; u otros de nivel intermedio, como los escribanos Alfonso Pérez de la Cámara o Juan Pérez de Carrión.

\subsection{Solariegos}

Tampoco vemos una relación directa entre los beneficiarios de situados en 1292 y los señores de 1352 en los solariegos, aunque sí hay algunos aspectos interesantes en los que merece la pena detenerse. Dos de los cinco casos reflejados en la Tabla 3 corresponden a señoríos compartidos en 1352, pero probablemente se trataba de herencias indivisas entre parientes. Es probable que fuera el caso de Villodre, en la merindad de Castrojeriz, en manos de Juan Fernández de Avanades, hijo de Fernán Fernández, y de Lope Fernández, hijo de Fernán Álvarez. Aquí en 1292 tenía un situado de 260 maravedís Gonzalo Ruiz de Atienza ${ }^{76}$. Pero con seguridad era el caso de Clunia, que había pertenecido a Juan Martínez de Leiva y a su esposa Juana por donación de Alfonso XI y en 1352, muerto ya el primero, estaba en manos de su viuda y de sus herederos, tanto los hijos e hijas habidos en su matrimonio con Juana como los que había tenido con otra esposa, Guiomar. Cuando Alfonso XI les entregó el señorío de Clunia, les dio también la martiniega, que era de 1.200 maravedís. Informa de todo ello el Becerro de las Behetrías, que nos dice también que hasta entonces la martiniega la llevaba el castillo del lugar por el rey; pero antes de eso la tuvo al menos la infanta Blanca, como se recoge en las rentas de $1292^{77}$.

También nos parece interesante el caso de Ubierna, señorío de García Fernández Manrique en 1352, quien tenía una proyección considerable en la zona por la procedencia de los Manrique respecto de los Manzanedo. Sin embargo, no figura ningún Manrique entre los beneficiarios de situados en 1292, ni en las martiniegas de la villa, ni en las del alfoz, ni en las de la merindad -aunque sí en otras villas de la zona, como Vivar del Cid, como señalaremos más adelante-. Pero en la villa de Ubierna sí tenían sendos situados de 900 maravedís Arias Díaz y Lope Rodríguez de Villalobos. No hay problema en identificar al primero con el ricohombre Arias Díaz de Asturias, a quien Sancho IV había dado unos años antes el lugar de Hontoria de Cerrato, cerca de Palencia, a cambio de Valles de Palenzuela, y no conocemos que él o su

\footnotetext{
${ }^{76}$ Hernández 1993, p. 30; Martínez 1981, XI-84.

${ }^{77}$ Hernández 1993, t. 1, p. 27; Martínez 1981, XV-88.
} 
familia tuvieran otros intereses en la zona de Ubierna ${ }^{78}$. Pero el segundo, Lope Rodríguez de Villalobos, sí los tenía y muy importantes e, igual que los de los Manrique, también procedían de los Manzanedo ${ }^{79}$.

En 1352 Villaquirán de los Infantes era de Pedro Ruiz Carrillo y el propio Becerro de las Behetrías nos indica que era un señorío reciente, puesto que se lo había dado Alfonso XI. De manera que podemos pensar que la villa era realengo en 1292 y el situado que entonces tenía en su martiniega Álvaro Rodríguez de Aza hay que interpretarlo en un contexto de realengo, no de solariego ${ }^{80}$.

La última villa que en 1352 es solariego teniendo un situado en 1292 es Villatuelda, en la merindad de Silos. El situado en 1292 lo tiene Mari Gutiérrez, ama de la reyna, que recibía todos los pechos e los derechos e los seruicios. Seguramente era una criada de la reina Violante -no de María de Molina, como cabría pensar-, a quien Sancho IV le había dado el lugar. Nos informa de ello el propio Becerro, puesto que indica que en 1352 el lugar era solariego de Pedro de Haro por herencia de la reina Violante -recuérdese el matrimonio de su hija, la infanta Violante, con Diego de Haro- ${ }^{81}$. De manera que, de nuevo, el situado de 1292 hay que interpretarlo no tanto en un contexto de solariego, sino más próximo al realengo, o a una forma especial de realengo, como eran los señoríos y la dotación de las reinas.

\subsection{Behetrías}

En las villas que en 1352 eran behetrías sí vemos una relación entre sus señores, bien señores singulares, bien naturales o diviseros, y los beneficiarios de situados en 1292. Es el caso de Vivar del Cid (en la merindad de Burgos, entre la ciudad de Burgos y Ubierna) cuyo señor singular en 1352 era García Fernández Manrique y donde tenía un situado en forma de heredamiento su abuelo homónimo ${ }^{82}$. También en Hormaza, Villamayor de Treviño y Villamorón (las tres en la merindad de Castrojeriz en 1292, aunque Villamayor en 1352 figura en la merindad de Villadiego) encontramos coincidencias significativas. En Hormaza tenía un situado en 1292 Lope Rodríguez de Villa-

\footnotetext{
${ }^{78}$ Serrano 1906, doc. LVI de 16 de septiembre de 1288.

${ }^{79}$ Sobre la relación entre los Manrique y los Villalobos como derivados de los Manzanedo, Estepa 2003, t. 1, p. 297.

${ }^{80}$ Hernández 1993, p. 28; Martínez 1981, XI-70.

${ }^{81}$ Hernández 1993, p. 27, donde se da la misma interpretación que ofrecemos aquí; Martínez 1981, XV-106.

${ }^{82}$ Hernández 1993, p. 33; Martínez 1981, XIII-58.
} 
lobos como vasallo del infante Fernando y la villa era behetría de los Villalobos en 1352, cuando también pagaba la martiniega a uno de ellos, entonces a Fernando Rodríguez de Villalobos (sobrino-nieto del anterior) ${ }^{83}$. En Villamayor de Treviño el situado en 1292 lo llevaba Pedro Fernández Cabeza de Vaca, mientras que varios Cabeza de Vaca, junto a los Tovar, eran los naturales en 1352 (no se conoce el nombre del señor singular) ${ }^{84}$. Y en Villamorón Alfonso Pérez de Villegas tenía un situado en 1292 y era behetría entre parientes de los Villegas en 1352, cuando además pagaban la martiniega a Sancho Ruiz Villegas y sus hermanos por donaçion que dizen que les fizo el rrey, aunque desconocemos el parentesco exacto entre uno y otros ${ }^{85}$.

En las otras cuatro behetrías con situados en 1292 no conocemos vínculos entre sus beneficiarios y los señores o naturales o diviseros en $1352^{86}$.

\subsection{Realengos}

También las villas que eran realengos en 1352 ofrecen algunas interesantes informaciones que relacionan los situados con el poder señorial. Siendo su señor nominalmente el rey en 1352, había distintas situaciones. Por ejemplo, Astudillo, en la merindad de Castrojeriz, pertenecía a la reina y era un lugar tradicionalmente asignado para la dotación de las reinas. La reina recibía también la martiniega en 1352 y en 1292 María de Molina se beneficiaba de un importante situado ${ }^{87}$. Es un caso similar a los de Ciadoncha y Villatuelda de los que hemos hablado más arriba.

Castrojeriz también era realengo en 1352 pero el Becerro de las Behetrías recoge la participación de varios nobles y del monasterio de Santa Clara en su martiniega. Una situación que ya vemos en 1292, con situados importantes para Pedro López de Padilla y Alfonso de Molina. La zona de Castrojeriz era el núcleo de los intereses señoriales de los Padilla y Pedro López y otros Padilla recibían otros situados en la zona, además de este, como hemos visto ${ }^{88}$.

En 1352 la villa de Pampliega pertenecía al concejo de Burgos. Se la habían vendido unos años antes, en 1331, la viuda y la hija de García Fernández

${ }^{83}$ Hernández 1993, p. 29; Martínez 1981, XI-51.

${ }^{84}$ Hernández 1993, p. 30; Martínez 1981, VI-47.

${ }^{85}$ Hernández 1993, p. 31; Martínez 1981, XI-44.

${ }^{86}$ Son Grijalba y Zorita en la merindad de Castrojeriz y Jaramillo Quemado y Lagunas en la merindad de Silos; Hernández 1993, pp. 29 y 26; Martínez 1981, XI-52 y 57 y XV-26 y 85.

${ }^{87}$ Hernández 1993, p. 29; Martínez 1981, XI-73.

${ }^{88}$ Hernández 1993, p. 30; Martínez 1981, XI-114. 
de Villamayor. Este, a su vez, la había obtenido por donación de Fernando IV en 1297. Sin embargo, ya antes de recibir el señorío sobre la villa disfrutaba de un situado en ella en $1292^{89}$.

Por último, el lugar que hemos incluido en la Tabla 3 como dudoso es Zayas, en la merindad de Silos, donde en 1292 disfrutaba de un situado la priora del monasterio de Brazacorta. Ese lugar puede corresponder a dos posibles entre los que figuran en el Becerro de las Behetrías, Zayas de Torre o Zayas de Bascones; pero, aunque ambos estaban muy cerca de Brazacorta, en ninguno de ellos tenía derechos señoriales ese monasterio en $1352^{90}$.

\section{CONCLUSIONES}

Si en el reinado de Alfonso VIII (1158-1214) ya se documenta que el dinero comienza a ser un referente en las relaciones políticas, las rentas de Sancho IV muestran la generalización de ese proceso a finales del siglo XIII. Es un proceso de gran importancia para entender tanto la evolución política como social y económica de Castilla en ese período. Hay muchos factores que han de ser considerados: la evolución de la expansión territorial, la relación entre la monarquía y la nobleza, el desarrollo del sistema fiscal o las acuñaciones monetarias, son algunos de los más importantes.

Pero la monetización de las relaciones políticas no eliminó en absoluto el papel de la tierra (los dominios y señoríos) como factor de generación de poder económico, social y político para la nobleza. Por ello la tierra seguirá siendo clave en la relación monarquía/nobleza y entre los distintos sectores nobiliarios.

En este artículo se ha querido iniciar una reflexión sobre esos aspectos. Una reflexión inicial que ha de ser completada teniendo en cuenta los factores que se han mencionado y otros más. Para ello se ha tomado como referencia la información que proporcionan los libros de rentas de Sancho IV en 1292 y el Becerro de las Behetrías en 1352. Los primeros nos hablan del dinero y el segundo de los señoríos y la comparación entre ambos arroja alguna luz sobre el proceso.

\footnotetext{
${ }^{89}$ Hernández 1993, p. 28; Martínez 1981, XII-73. Sobre la adquisición por el concejo de Burgos, Bonachía 1988, pp. 39-40; y los documentos en González 1984, docs. 178 y 179.

${ }^{90}$ Hernández 1993 , p. 27; Martínez 1981, XV-77 y 78. Zayas de Torre en 1352 era condominio del monasterio de Fuencaliente y de varios nobles laicos, Zayas de Bascones era solariego de Sancho Ruiz de Zayas.
} 
El sistema de pagos de soldadas, situados y quitaciones era amplísimo y todavía desconocido en muchos aspectos. Las rentas que los nobles recibían del rey y sus derechos señoriales se superponían en muchas ocasiones, pero tampoco era una superposición perfecta, por que los segundos, aunque no exentos de dinamismo, eran bastante más estáticos que las primeras, que reflejan con más rapidez los cambios en las relaciones políticas.

La concentración del poder señorial en beneficio de la alta nobleza, que muestra el Becerro de las Behetrías a mediados del siglo XIV, tiene su paralelo también en la concentración de situados a su favor que vemos en las rentas de fines del siglo XIII. Aunque las cifras han de valorarse como indicadores de tendencias, son bastante concluyentes. Los ricoshombres recibían casi el $65 \%$ de las rentas situadas y los caballeros algo más del $25 \%$. En todo caso, ambos grupos prácticamente monopolizaban el sistema con el 90\% de las rentas distribuidas.

Por otro lado, nos parece relevante destacar que encontramos más relación entre las rentas y los derechos señoriales en el grupo de los caballeros que en el de los ricoshombres.

Los situados se extendían por todas las formas señoriales. En relación con ello, el análisis propuesto se ha de completar y ampliar geográficamente, pero encontramos mayor concentración de situados a oficiales y criados en villas de abadengo, lo que indicaría una mayor capacidad de disposición de las rentas de esos lugares por el rey, al margen de su situación señorial. Lo contrario, la relación más estrecha entre beneficiarios de situados y señores se da en las behetrías y no parece difícil concluir que los situados fueran también una forma de reforzar la posición de algunos diviseros para hacerse con el señorío singular de las behetrías.

Por consiguiente, hemos podido ver cómo el sistema de situados se había generalizado a finales del siglo XIII y cómo algunos señores reforzaban su posición señorial a través de los situados. Estudiar cómo se desenvolvió el proceso desde los primeros pasos en el reinado de Alfonso VIII hasta su generalización ya en el de Sancho IV nos parece una tarea del mayor interés que ha de abordarse en futuros trabajos. 


\section{APÉNDICE DE TABLAS}

Tabla 1. Cantidades totales situadas en 1292

\begin{tabular}{|l|c|c|c|}
\hline \multicolumn{1}{|c|}{ RENTA } & CANTIDAD & BENEFICIARIOS & MEDIA \\
\hline Merindad de Burgos & 22.880 & 12 & $1.906,67$ \\
\hline Merindad de Castrojeriz & 35.547 & 19 & $1.870,89$ \\
\hline $\begin{array}{l}\text { Merindad de Lerma y } \\
\text { Covarrubias }\end{array}$ & 9.496 & 3 & $3.165,33$ \\
\hline Merindad de Muñó & 16.520 & 5 & $3.304,00$ \\
\hline Merindad de Silos & 23.428 & 9 & $2.603,11$ \\
\hline Judíos de Burgos & 111.925 & 28 & $3.997,32$ \\
\hline Judíos de Castrillo & 6.720 & 1 & $6.720,00$ \\
\hline $\begin{array}{l}\text { Judíos de Lerma, Muñó y } \\
\text { Palenzuela }\end{array}$ & 9.882 & 4 & $2.470,50$ \\
\hline Tercias de Burgos & 47.250 & 14 & $3.375,00$ \\
\hline TOTAL & 283.648 & $69^{*}$ & $4.110,84$ \\
\hline
\end{tabular}

* La suma total de beneficiarios (69) no corresponde a la suma de los beneficiarios de las distintas rentas (95), porque varios de ellos tienen situados en distintas rentas. Nuestras sumas difieren ligeramente de las del editor de los textos; por ejemplo, Hernández 1993, p. LXXXVII.

Tabla 2. Tipos de beneficiarios de situados en 1292. Cifras totales

\begin{tabular}{|l|c|r|r|r|r|}
\hline \multicolumn{1}{|c|}{ BENEFICIARIOS } & NÚMERO & \multicolumn{1}{c|}{$\%$} & \multicolumn{1}{c|}{ CANTIDAD } & \multicolumn{1}{c|}{$\begin{array}{c}\text { CANTIDAD } \\
\text { MEDIA }\end{array}$} \\
\hline Eclesiásticos & 5 & $7,24 \%$ & 3.300 & $1,16 \%$ & 660,00 \\
\hline $\begin{array}{l}\text { Ricoshombres y } \\
\text { familia real }\end{array}$ & 20 & $28,98 \%$ & $181.863,5$ & $64,12 \%$ & $9.093,18$ \\
\hline Caballeros & 30 & $43,47 \%$ & $71.515,5$ & $25,21 \%$ & $2.383,85$ \\
\hline Oficiales & 11 & $15,94 \%$ & 25.309 & $8,92 \%$ & $2.300,82$ \\
\hline Criados & 3 & $4,34 \%$ & 1.660 & $0,59 \%$ & 553,33 \\
\hline TOTAL & 69 & $99,97 \%$ & 283.648 & $100 \%$ & $4.110,84$ \\
\hline
\end{tabular}


Tabla 3. Lugares individuales con situados en 1292 y su situación señorial en 1352

\begin{tabular}{|l|c|l|l|c|c|c|c|}
\hline \multicolumn{9}{|l|}{} & \multicolumn{5}{l|}{ SEÑORÍO EN 1352 } \\
\hline MERINDAD & $\begin{array}{l}\text { No DE } \\
\text { LUGARES } \\
\text { CON } \\
\text { SITUADOS } \\
\text { EN 1292 }\end{array}$ & $\begin{array}{l}\text { LUGARES } \\
\text { INCLUIDOS } \\
\text { EN EL } \\
\text { BECERRO } \\
\text { DE LAS } \\
\text { BEHETRÍAS }\end{array}$ & REALENGOS & ABADENGOS & SOLARIEGOS & BEHETRÍAS & DUDOSO \\
\hline Silos & 6 & 6 & 0 & 1 & 2 & 2 & 1 \\
\hline $\begin{array}{l}\text { Muñó y } \\
\text { Lerma }\end{array}$ & 5 & 5 & 1 & 3 & 1 & 0 & 0 \\
\hline Castrojeriz & 10 & 8 & 2 & 0 & 1 & 5 & 0 \\
\hline Burgos & 6 & 5 & 0 & 3 & 1 & 1 & 0 \\
\hline TOTAL & 27 & 24 & 3 & 7 & 5 & 8 & 1 \\
\hline
\end{tabular}

Tabla 4. Situados sobre villas en 1292 a favor de oficiales y criados regios

\begin{tabular}{|c|c|c|c|}
\hline $\begin{array}{l}\text { LUGAR / } \\
\text { MERINDAD }\end{array}$ & BENEFICIARIO & CANTIDAD / CONCEPTO & $\begin{array}{l}\text { SITUACIÓN } \\
\text { SEÑORÍAL } 1352\end{array}$ \\
\hline $\begin{array}{l}\text { Encío } \\
\text { M. Burgos, } \\
\text { p. } 33\end{array}$ & $\begin{array}{l}\text { Aldonza López, "couigera" } \\
\text { de la reina }\end{array}$ & $\begin{array}{l}\text { Cantidad sin especificar. } \\
\text { Como heredamiento }\end{array}$ & $\begin{array}{l}\text { Abadengo } \\
\text { XIV-2 y } 275 / 2\end{array}$ \\
\hline $\begin{array}{l}\text { Ciadoncha } \\
\text { M. Muñó, } \\
\text { p. } 28\end{array}$ & $\begin{array}{l}\text { Fernán Pérez, canciller de } \\
\text { la reina }\end{array}$ & $\begin{array}{l}3.000 \mathrm{~m} . \\
\text { Como heredamiento }\end{array}$ & $\begin{array}{l}\text { Abadengo } \\
\text { XII- } 63\end{array}$ \\
\hline $\begin{array}{l}\text { Mecerreyes } \\
\text { M. Lerma, } \\
\text { p. } 34\end{array}$ & Juan Mathé, camarero & $\begin{array}{l}\text { Cantidad sin especificar. } \\
\text { Como heredamiento en los } \\
\text { derechos }\end{array}$ & $\begin{array}{l}\text { Abadengo } \\
\text { XII-33 }\end{array}$ \\
\hline $\begin{array}{l}\text { Ruyales } \\
\text { M. Lerma, } \\
\text { p. } 34\end{array}$ & Juan Mathé, camarero & $\begin{array}{l}\text { Cantidad sin especificar. } \\
\text { Como heredamiento en los } \\
\text { derechos }\end{array}$ & $\begin{array}{l}\text { Abadengo } \\
\text { XII-35 }\end{array}$ \\
\hline $\begin{array}{l}\text { Villayuda } \\
\text { M. Burgos, } \\
\text { p. } 33\end{array}$ & $\begin{array}{l}\text { Juan Pérez de Carrión } \\
\text { durante su vida. El } 1 \text { de } \\
\text { agosto de } 1288 \text { le dio el } \\
\text { rey todos los pechos de } \\
\text { Villayuda. }\end{array}$ & $\begin{array}{l}60 \mathrm{~m} . \\
\text { Como heredamiento en la } \\
\text { martiniega }\end{array}$ & $\begin{array}{l}\text { Abadengo } \\
\text { XIII-53 }\end{array}$ \\
\hline
\end{tabular}




\begin{tabular}{|l|l|l|l|}
\hline $\begin{array}{l}\text { Grijalba } \\
\text { M. Castrojeriz, } \\
\text { p. 30 }\end{array}$ & Alfonso Pérez de la Cámara & $\begin{array}{l}\text { 42 m. Es el valor de 7 } \\
\text { cargas de pan }\end{array}$ & $\begin{array}{l}\text { Behetría } \\
\text { XI-52 }\end{array}$ \\
\hline $\begin{array}{l}\text { Villatuelda } \\
\text { M. Silos, p. 27 }\end{array}$ & $\begin{array}{l}\text { Mari Gutiérrez, ama de la } \\
\text { reina }\end{array}$ & $\begin{array}{l}\text { Cantidad sin especificar. } \\
\text { En los pechos, los } \\
\text { derechos y los servicios }\end{array}$ & $\begin{array}{l}\text { Solariego } \\
\text { XV-106 }\end{array}$ \\
\hline $\begin{array}{l}\text { Villamayor } \\
\text { ¿de Treviño? }\end{array}$ & $\begin{array}{l}\text { Pedro Fernández Cabeza } \\
\text { de Vaca, merino mayor de } \\
\text { León }\end{array}$ & $\begin{array}{l}\text { 180 m. } \\
\text { Los tenía como } \\
\text { heredamiento y ahora los } \\
\text { tiene en tierra }\end{array}$ & ¿Behetría \\
\hline
\end{tabular}

\section{BIBLIOGRAFÍA CITADA}

Álvarez Borge, Ignacio (1996a), Los señoríos en Castilla la Vieja a mediados del siglo XIV, "Studia Historica. Historia Medieval" 14, pp. 181-220.

Álvarez Borge, Ignacio (1996b), Poder y relaciones sociales en Castilla en la Edad Media, Valladolid, Junta de Castilla y León.

Álvarez Borge, Ignacio (2015), Soldadas, situados y fisco regio en el reinado de Alfonso VIII de Castilla (1158-1214), "Journal of Medieval Iberian Studies" 7/1, pp. 57-86.

Álvarez Borge, Ignacio (2016), Patrimonio, rentas y poder de la nobleza bajomedieval peninsular, en Discurso, memoria y representación. La nobleza peninsular en la Baja Edad Media.XLII Semana de Estudios Medievales de Estella, Pamplona, Gobierno de Navarra, pp. 83-140. Álvarez Borge, Ignacio (2019), Crisis política y relaciones señoriales en la frontera del Ebro en la primera mitad del siglo XIV. Algunos ejemplos, en Val Valdivielso, M. ${ }^{\text {a }}$ Isabel del; Martín Cea, Juan Carlos; Carvajal de la Vega, David (eds.), Expresiones del poder en la Edad Media. Homenaje al profesor Juan Antonio Bonachía Hernando, Valladolid, Universidad de Valladolid, pp. 141-150.

Álvarez Borge, Ignacio (en prensa), Notas sobre geografía fiscal en Castilla la Vieja a finales del siglo XIII. Merindades, villas y otros distritos.

Bonachía Hernando, Juan Antonio (1988), El señorío de Burgos durante la Baja Edad Media (1255-1508), Valladolid, Junta de Castilla y León.

Estepa Díez, Carlos (1994), Estructuras de poder en Castilla (siglos XII-XIII). El poder señorial en las merindades burgalesas, en Burgos en la Plena Edad Media, Burgos, Asociación Provincial de Libreros.

Estepa Díez, Carlos (2003), Las behetrías castellanas, Valladolid, Junta de Castilla y León, 2 vols. 
Estepa Díez, Carlos (2007), La monarquía castellana en los siglos XIII-XIV. Algunas consideraciones, "Edad Media. Revista de Historia” 8, pp. 79-98.

Estepa Díez, Carlos (2015), War and taxation from the reign of Alfonso VIII of Castile to the $13^{\text {th }}$ century, "Imago temporis. Medium Aevum" 9, pp. 211-223.

Estepa Díez, Carlos; Jular Pérez-Alfaro, Cristina (2009), Castilian behetría lordship: from current perspectives towards a European context, en Estepa Díez, Carlos; Jular Pérez-Alfaro, Cristina (eds.), Land, power and society in medieval Castile. A study of behetría lordship, Turhout, Brepols, pp. 1-27.

Gaibrois, Mercedes (1922-1928) Historia del reinado de Sancho IV de Castilla, Madrid, Revista de Archivos Bibliotecas y Museos, 3 vols.

González Díez, Emiliano (1984), Colección diplomática del concejo de Burgos (884-1369), Burgos, Ayuntamiento de Burgos.

González Mínguez, César (2012), Poder real y poder nobiliario en la Corona de Castilla (1252-1369), Bilbao, Universidad de País Vasco.

Grassotti, Hilda (1969), Las instituciones feudo-vasalláticas en León y Castilla, Spoleto, Centro italiano di studi sull'alto Medioevo, 2 vols.

Hernández, Francisco Javier (1993), Las rentas del rey. Sociedad y fisco en el reino castellano del siglo XIII, Madrid, Fundación Ramón Areces, 2 vols.

Ladero Quesada, Miguel Ángel (1993), Fiscalidad y poder real en Castilla (1252-1369), Madrid, Editorial Complutense.

López Dapena, Asunción (1984), Cuentas y gastos (1292-1294) del rey D. Sancho IV el Bravo (1284-1295), Córdoba, Monte de Piedad y Caja de Ahorros.

Martínez Díez, Gonzalo (1981), Libro Becerro de las Behetrías. Estudio y texto crítico, León, Centro de Estudios e Investigación San Isidoro, 3 vols.

Monsalvo Antón, José María (2017), El conflicto 'nobleza frente a monarquía' en el contexto de las transformaciones del estado en la Castilla Trastámara. Reflexiones críticas, en Jara Fuente, José Antonio (coord.), Discurso político y relaciones de poder. Ciudad, nobleza y monarquía en la Baja Edad Media, Madrid, Dykinson, pp. 89-287.

Monsalvo Antón, José María (2019), La construcción del poder real en la Monarquía castellana (siglos XI-XV), Madrid, Marcial Pons.

Moxó, Salvador de (1969), De la nobleza vieja a la nobleza nueva. La transformación nobiliaria castellana en la Baja Edad Media, "Cuadernos de Historia (Anexos de la revista Hispania)" 3, pp. 1-210. 
Negro Cortés, Adrián Elías (2018), Las parias en la Historia Medieval española, en Sabaté, Flocel; Brufal, Jesús (coords.), Investigar l'Edat Mitjana, Lérida, Pagés, pp. 43-54.

Nieto Soria, José Manuel (1994), Sancho IV, 1284-1295, Palencia, La Olmeda. Pastor y Díaz de Garayo, Ernesto (2002), Las relaciones feudo-vasalláticas en la Castilla del siglo XI. Reorganización de los poderes y dialéctica de la frontera, en Bonnassie, Pierre; Cursente, Benoît; Débax, Hélène (coords.), Fiefs et féodalité dans l'Europe méridionale (Italie, France du Midi, Péninsule ibérique) du Xe au XIII siècle, Toulouse, CNRS, pp. 313-361.

Reglero de la Fuente, Carlos Manuel (2016), Las 'señoras' de las Huelgas de Burgos: infantas monjas y encomenderas, "e-Spania” 24, publicado on-line el 15 de junio de 2016, http://e-spania.revues.org/25542 [consultado: 26/11/2016]; DOI: 10.4000/e-spania.25542.

Rossell, Cayetano (ed.) (1953), Crónicas de los Reyes de Castilla, vol. I, t. 66, Madrid, Biblioteca de Autores Españoles, pp. 14-392.

Sánchez Saus, Rafael (2006), Los caballeros jerezanos en la 'Nómina de la Frontera' de 1290, "En la España Medieval” 29, pp. 31-51.

Serrano, Luciano (1906), Colección diplomática de San Salvador de El Moral, Valladolid, Tipografía y Casa Editorial Cuesta.

Vázquez Campos, Braulio (2004), Hacienda regia, jerarquía social y grandes oficios, "Historia, Instituciones y Documentos" 31, pp. 701-714.

Vivancos, Miguel Carlos (1995), Documentación del monasterio de Santo Domingo de Silos (1255-1300), Santo Domingo de Silos, Abadía de Santo Domingo de Silos.

Fecha de recepción del artículo: octubre 2019

Fecha de aceptación y versión final: marzo 2020 